\title{
SPATIO-TEMPORAL ASSESSMENT OF LAND USE/ LAND COVER DYNAMICS AND URBAN HEAT ISLAND OF JAIPUR CITY USING SATELLITE DATA
}

\author{
Seema Jalan ${ }^{\text {a }}$, Kavita Sharma ${ }^{\mathrm{b}, *}$ \\ a Department of Geography, Mohanlal Sukhadia University, Udaipur-seemajalan1@gmail.com \\ ${ }^{b}$ Department of Geography, University of Rajasthan, Jaipur -kavitasharma2712@gmail.com
}

KEY WORDS: Urban, Temperature, Land use, Land cover, Landsat

\begin{abstract}
:
Urban Heat Island (UHI) refers to the phenomena of higher surface temperature occurring in urban areas as compared to the surrounding countryside attributable to urbanization. Spatio-temporal changes in UHI can be quantified through Land Surface Temperature (LST) derived from satellite imageries. Spatial variations in LST occur due to complexity of land surface - combination of impervious surface materials, vegetation, exposed soils as well as water surfaces. Jaipur city has observed rapid urbanization over the last decade. Due to rising population pressure the city has expanded considerably in areal extent and has also observed substantial land use/land cover (LULC) changes. The paper aims to determine changes in the LST and UHI phenomena for Jaipur city over the period from 2000 to 2011 and analyzes the spatial distribution and temporal variation of LST in context of changes in LULC. Landsat 7 ETM+ (2000) and Landsat 5 TM (2011) images of summer season have been used. Results reveal that Jaipur city has witnessed considerable growth in built up area at the cost of greener patches over the last decade, which has had clear impact on variation in LST. There has been an average rise of $2.99^{\circ} \mathrm{C}$ in overall summer temperature. New suburbs of the city record $2^{\circ}$ to $4^{\circ} \mathrm{C}$ increase in LST. LST change is inversely related to change in vegetation cover and positively related to extent of built up area. The study concludes that UHI of Jaipur city has intensified and extended over new areas.
\end{abstract}

\section{INTRODUCTION}

\subsection{Background}

Global warming has drawn attention of researchers worldwide because the global mean surface temperature has recorded an increase since the late $19^{\text {th }}$ century. As more than $50 \%$ of the human population lives in cities, urbanization has been an important contributor in the process of global warming. Temperature changes consequent upon the transformations of physical landscape associated with urbanization have led to many environmental problems. One such consequence is Urban Heat Island (UHI).

UHI refers to the phenomena of higher surface temperature occurring in urban areas as compared to the surrounding countryside attributable to urbanization. Extensive urbanized surfaces modify the energy and water balance processes and influence the dynamics of air movement (Oke, 1987). The interactions of urban surfaces with the atmosphere are governed by surface heat fluxes, the distribution of which is drastically modified by urbanization. The main contributing factors are changes in physical characteristics of the surface (albedo, thermal capacity, heat conductivity) owing to replacement of vegetation by asphalt and concrete; decrease of surface moisture available for evapo-transpiration; changes in radiative fluxes and in near surface flow, owing to complicated geometry of streets and tall buildings, and anthropogenic heat (Dousset and Gourmelon, 2003). The integrated application of remote sensing, geographic information system (GIS) and quantitative analytical modeling can provide scientific and effective methods for monitoring and studying urban land surface thermal environment (Dai et al., 2010).

* Corresponding author
Land surface temperature (LST) is a key factor in physical processing of land surface at a regional and global scale, and it generalizes the results of the interaction between land surface and atmosphere, exchange of matter and energy (Wan and Dozier, 1996). In the general assessment model of sustainable development and LST change, the change of LST is regarded as an important criterion upon which the evaluation of environmental quality and social and economic development policy can be based (Janssen, 1998; Tamerius et. al., 2007; Keller, 2008; Dai et. al., 2009). LST retrieval from thermal infrared band data of remote sensors has become one of the major approaches to obtain information about LST spatiotemporal distribution (Gallo et. al. 1995; Owen et. al. 1998).

Characteristics of UHI have been studied extensively in recent years. Weng, Q. (2009) provides an exhaustive account of current practices, methods, problems and prospects in the field of thermal remote sensing. The earliest UHI study was conducted in 1965 in the urban southern Singapore (Nieuwolt, 1966). Subsequently, significant research has been done to study the diurnal, seasonal and spatio-temporal characteristics of urban thermal environment and identification of appropriate indices to quantify the bio-physical and demographic characteristics of urban landscape to explain the LST variations. Deosthali (2000) found that at night, core of the city appeared as both heat and moisture island whereas at the time of sunrise as heat and dry island. Saaroni et al. (2000) adopted a new combined method of monitoring the UHI from different levels and on different scales, which enabled a spatial assessment of the city's UHI and its diverse thermal coverage characteristics. Findings of Kim \& Baik (2002) reveal that average maximum UHI is weakest in summer and strong in autumn and winter. The UHI intensity was found to be inversely correlated with the rural temperature, while the spatial extent was found to be independent of both heat island magnitude and rural temperature by Streutker (2002). Giridharan et al. (2004) 
studied the daytime UHI effect in high-rise and high-density residential developments in Hong Kong. Hawkins et al. (2004) studied the effect of rural variability in calculating the urban heat island effect.

Xiao et. al. (2008) identify quantification of statistical relationship between LST and land use land cover parameters as a relatively neglected field of research in the field of thermal remote sensing. They quantitatively analyzed LST variations in context of bio-physical and demographic variables. It was found that LST is positively correlated with built up area and population density, while negative association exists between LST and percentage of forest, farmland and water bodies. Positive relationship between LST and fraction of impervious surface, and negative association between LST and fraction of green vegetation cover has been corroborated by the findings of Weng et. al. (2007), Buyantuyev and Wu (2010), and Li et. al (2014). Weng et. al. (2007) suggest that each temperature zone is associated with a dominant land use land cover category. Buyantuyev and $\mathrm{Wu}$ (2010) studied diurnal and seasonal characteristics of the surface UHI in relation to land cover properties and observe that vegetation is the most significant explanatory variable of daytime surface temperature. Chen et. al. (2006) studied UHI in relation with land use land cover changes and identified seasonal variations in UHI intensity. They further observe that agricultural activities have an obvious influence on the interpretation of land use land cover types. Li et al. (2014) have studied LST variations for over a decade (2000-2009) using multi-temporal Landsat data and find that high LST regions correspond with residential and industrial areas with low vegetation coverage. Low population density is associated with lower LST values. Nevertheless, seasonal analysis of relationship between LST and percent impervious surface and NDVI done by Yuan and Bauer (2007) reveals that relationship between NDVI and LST varies seasonally. They suggest percent impervious surface cover as a more reliable metric for quantitative analysis of LST over different seasons for urbanized areas.

Studies have established that UHI intensity is related to patterns of land use/cover changes, e.g., the composition of vegetation, water and built-up and their changes over a specific period. Various vegetation indices obtained from remote sensing images can be used in the assessment of vegetation cover qualitatively and quantitatively (Tian \& Xiangjun, 1998). Qualitative and quantitative studies on the relationship between land use/cover pattern and LST are imperative for effective urban land use planning.

Jaipur city is the capital and administrative headquarter of Rajasthan, the largest state of India. The city has witnessed high population growth especially in the past decade. Consequently, there has been a remarkable acceleration in construction activities for industries, institutional infrastructure and residential colonies etc. Although several researches have studied urban expansion of the city and associated LULC changes but there has hitherto been no study on the impact of LULC changes on thermal environment of the city. Present paper is a preliminary attempt to fill this research gap. Changes in LULC pattern in the rapidly urbanizing Jaipur Municipal Corporation (JMC) area have been examined since year 2000 and impact of changes in physical landscape on the intensity and spatial pattern of UHI effect in the region has been investigated. Cardinal objectives of the study are: (1) to determine changes in the LST and UHI phenomena for Jaipur city over the past decade (2000-2011); (2) to analyze the spatial distribution and temporal variation of surface temperature in context of changes in LULC particularly urban greenery and built up area; and (3) to examine the potential of remote sensing technology for the selected application.

\section{DATA AND METHODS}

\subsection{Study Area}

Jaipur city is situated in the eastern semi-arid part of Rajasthan and lies between $26^{\circ} 52^{\prime}$ and $26^{\circ} 57^{\prime}$ north latitudes and $75^{\circ} 47^{\prime}$ and $75^{\circ} 52^{\prime}$ east longitudes. It is the $10^{\text {th }}$ largest city of India (Census, 2011). It is one of the country's million-plus cities and the only city of this rank in Rajasthan. It also has one of the highest population growth rates. In 2001 urban population of Jaipur city was 2.3 million which accounted for 34.85 percent of the total population of Jaipur district and 17.57 percent of the total urban population of Rajasthan State as a whole. As per Census 2011, the same has increased to 3.07 million which constitutes 46.07 percent of total population of Jaipur district and 18.01 percent of total urban population of Rajasthan (Census of India, 2001 and 2011). The city is bound to have increased spatial expansion in the coming decades in order to accommodate both economic as well as population growth (JDA Master Plan, 2011). Effective land use planning is therefore essential to ensure sustainable growth of the city.

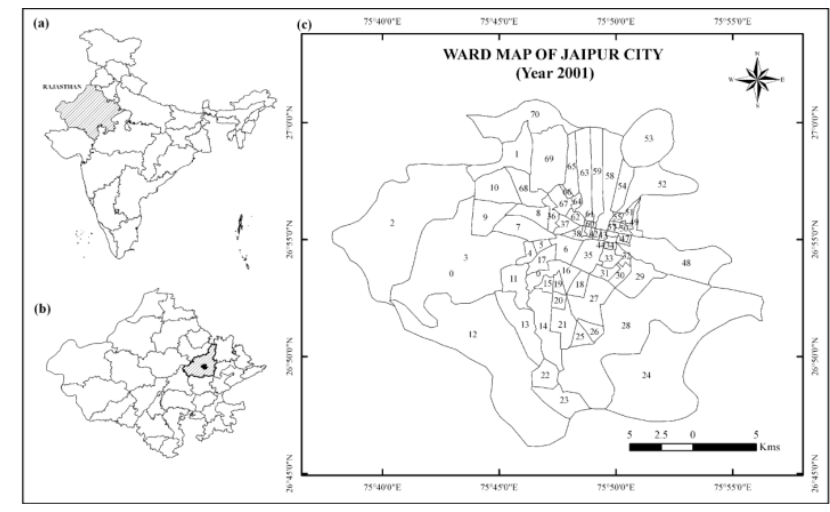

Figure 1. Location map (a) Location of Rajasthan in India (b) Location of Jaipur city in Rajasthan, and (c) JMC area

The study area comprises Jaipur Municipal Corporation (JMC) area of the city (Figure 1). JMC area has witnessed rapid urbanization during the past decade characterized by fast spatial expansion along with an accelerated population growth. In 2001 JMC area spread over 462 sq. km. comprising of 70 wards which has expanded by 5 sq. km. over the decade with 77 wards spreading across an area of 467 sq. km. in 2009. Population of the city has witnessed an increase of 7.7 lakhs during the past decade with a phenomenal growth rate of 33.5 percent. The city is bound by Nahargarh and Jamwa Ramgarh hills on the north and Jhalana hills in the east. Within these topographical constraints growth of built-up area has hitherto been mainly in the south, south-west and west.

\subsection{Data Used}

A set of cloud free imagery of summer season, Landsat-7 Enhanced Thematic Mapper Plus (ETM+) image acquired on $24^{\text {th }}$ May, 2000 and Landsat-5 Thematic Mapper (TM) acquired on $31^{\text {st }}$ May, 2011 have been used. Field data has been collected for identified sample sites for classification and as reference 
data for accuracy assessment of classified image. Thermal band (Band 6) has been used for extraction of LST.

\subsection{Image Pre-processing}

Data pre-processing forms an integral and vital component of data processing workflow for image classification and derivation of surface temperature map. Both datasets have been rectified to a common UTM (Universal Transverse Mercator) projection and WGS 84 datum and resampled using the nearest neighbor algorithm. Standard atmospheric parameters along with geometric parameters were estimated as per the guidelines prescribed on the official website of NASAhttp://atmcorr.gsfc.nasa.gov/ and were applied to satellite data for atmospheric corrections. The thermal band of TM has been resampled to match the pixel size to other bands, thus preserving 30-meter resolution of the data. After applying radiometric and geometric corrections spectral radiance image was derived from thermal band of both images.

\subsection{Derivation of LST}

Pixel level LST has been derived from thermal band as per the method proposed by Chen et al. (2002). Pixel level mean LST and standard deviation has been computed to assess the overall characteristics of temperature distribution for each year. Ward level mean LST has been computed and zonal level change in LST has been analyzed in context of changes in nature and extent of built up area and urban greenery.

2.4.1 Retrieval of Land Surface Temperature from Landsat 5 TM image: Landsat 5 TM 1G product has been utilized for retrieving temperature in 2011. First, DN values of band 6 are converted to radiance luminance (RTM6$\left.\mathrm{m} W^{*} \mathrm{~cm}^{-2} \mathrm{sr}^{-1}\right)$ on the basis of pre-launch calibration constants (Schott and Volchok, 1985) using Equation (1)

$$
\mathrm{R}_{\mathrm{TM} 6}=\frac{V}{255}\left(R_{\text {max }}-R_{\text {min }}\right)+R_{\text {min }}
$$

where $\quad V=\mathrm{DN}$ of band 6

$$
\begin{aligned}
& R_{\text {max }}=1.896\left(\mathrm{~m}^{*} \mathrm{~cm}^{-2 *} s r^{-1}\right) \\
& R_{\text {min }}=0.1534\left(\mathrm{~mW}^{*} \mathrm{~cm}^{-2 *} s r^{-1}\right)
\end{aligned}
$$

Second, the radiation luminance is converted to at-satellite brightness temperature Kelvin T ( $K$ ) using Equation (2)

$$
T(K)=\frac{K_{1}}{\operatorname{In}\left(K_{2} /\left(R_{T M 6}\right)+1\right)}
$$

where $\quad \begin{aligned} & K_{1}=607.66\left(\mathrm{~m} W^{*} \mathrm{~cm}^{-2 *} s r^{-1} \mu \mathrm{m}^{-1}\right) \\ & K_{2}=1260.56(\text { Kelvin }) \\ & K_{1} \& K_{2} \text { are pre-launch calibration constants } \\ & b=1.239(\mu \mathrm{m}) \text { effective spectral range, when the } \\ & \text { sensor's response is much more than } 50 \%\end{aligned}$

2.4.2 Retrieval of Land Surface Temperature from Landsat 7 ETM+ Image: Landsat 7 ETM+ $1 \mathrm{G}$ product has been utilized for retrieving temperature in 2000 following the approach described in the Landsat 7 User's handbook. It is also simplified into two steps as follows:

First, the DNs of bands have been converted to radiance using Equation (3)

$$
\text { Radiance }=\text { gain } * \mathrm{DN}+\text { offset }
$$

This can also be expressed as:

$$
\begin{aligned}
\text { Radiance }= & (\text { LMAX }- \text { LMINI QCALMAX }- \text { QCALMIN }) * \\
& (\text { QCAL }- \text { QCALMIN })+\text { LMIN }
\end{aligned}
$$

The gain and offset have been obtained from the header file of the images, QCALMIN $=1$, QCALMAX $=255$, QCAL=DN, and LMAX and LMIN (also given in the header file of the images) are the spectral radiances for band 6 at digital numbers 1 and 255 (i.e., QCALMIN and QCALMAX) respectively.

The effective at-satellite temperature of the viewed atmosphere system under the assumption of a uniform emissivity has been obtained from the above spectral radiance by the following equation:

$$
T=\frac{K 2}{\ln \left(\frac{K 1}{L \kappa}+1\right)}
$$

Where, $T$ is effective at-satellite brightness temperature in Kelvin; $\quad K l=666.09 \quad\left(\mathrm{~m} W^{*} \mathrm{~cm}^{-} \quad 2 * s r^{-} \quad{ }^{1} \mu \mathrm{m}^{-} \quad{ }^{1}\right)$ and $K 2=1282.71$ (Kelvin) are calibration constants; and $L K$ is the spectral radiance $\left(\mathrm{mW}^{*} \mathrm{~cm}^{-2 *} s r^{-1} \mu \mathrm{m}^{-1}\right)$.

\subsection{Image Classification}

Supervised classification using Maximum Likelihood Classifier has been performed on combination of Band 4 (NIR), Band 3 (Red) and Band 2 (Green) on both images to map the aggregate land cover of the study area during both the years. Images have been classified into seven classes-high dense built-up, low dense built-up, agriculture cropland, scrubs and bare soil, sparse vegetation, dense vegetation and water bodies. Areas comprising of inner city, central business district characterized by very little or no vegetation and high density of built up structures have been defined as high dense built up area. Built up area characterized by low density of buildings with some vegetation or sparsely built up area within city having open areas in between has been categorized as low dense built up area. The reserved forest area with high tree density has been classified as dense vegetation and scattered urban green areas like playgrounds, parks, lawns and roadside vegetation etc. have been defined as sparse vegetation.

Accuracy assessment of each classified image was performed using 280 reference pixels identified through stratified random sampling. Table 2 presents the results of accuracy assessment of both the classified maps. Subsequently, classified images have been compared visually as well as quantitatively to detect and measure the patterns and magnitude of changes in selected land cover categories which have occurred in 2011 as compared to 2000 .

High classification accuracy has been achieved for all the selected classes in both the classified maps. Overall accuracy (OA) for both years is more than 85 percent along with fairly high Kappa (K) statistics of approximately 80 percent and higher which indicates high reliability of classification results. Further the classwise accuracies for both years particularly User's Accuracy (UA) for individual classes is more than 80 percent for almost all classes of interest. Only exceptions are sparse vegetation class for which the UA for 2000 is 72.69 percent, and scrub and bare soil class for which UA is 66.67 percent for 2011. Relatively low accuracy of these classes may be attributed to mixed nature of classes in terms of land cover. 


\begin{tabular}{|l|ll|ll|}
\hline \multirow{2}{*}{ LULC Class } & \multicolumn{2}{|c|}{2000} & \multicolumn{2}{c|}{2011} \\
& PA & UA & PA & UA \\
\hline High Dense built Up & 87.15 & 83.79 & 88.98 & 81.99 \\
Low Dense Built Up & 68.98 & 90.35 & 85.37 & 91.12 \\
Agriculture Cropland & 92.27 & 90.59 & 88.32 & 82.70 \\
Sparse Vegetation & 83.17 & 72.69 & 78.34 & 82.77 \\
Dense Vegetation & 89.41 & 88.30 & 96.93 & 92.93 \\
Water Bodies & 100 & 99.87 & 100 & 100 \\
Scrubs and Bare Soil & 96.14 & 88.94 & 97.76 & 66.67 \\
\hline & OA=86.38 & OA=89.81 \\
& K=0.7903 & K=0.8466 \\
\hline
\end{tabular}

Table 2. Accuracy statistics of classified land use/land cover maps

NDVI images have been generated for both years as a measure of vegetation abundance, using band 3 and band 4 of the datasets. Pixel level correlation between LST and NDVI has been calculated to substantiate the observed relationship statistically.

\section{RESULT AND DISCUSSION}

\subsection{Spatial Distribution of Land Use Land Cover}

Figure 3 (a) and (b) show the spatial distribution of LULC in the study area in year 2000 and 2011 respectively. Figure 4 illustrates the relative magnitude and direction of change in the extent of selected classes over the past decade.

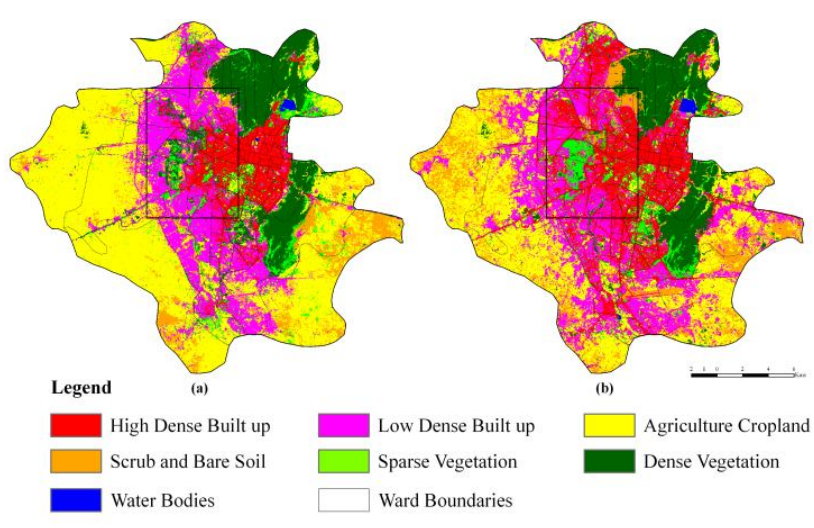

Figure 3. Land use land cover maps (a) 2000 (b) 2011

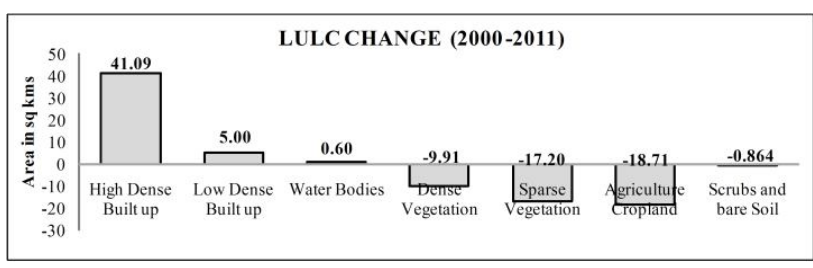

Figure 4. Change in extent of selected land use land cover categories from 2000 to 2011
Built up area of the city has increased both in form of physical expansion as well as internal densification. Both high and low dense built up area has increased but the increase in high dense built up area has been phenomenal which has increased by 41.09 percent. The expansion has primarily been radial and has been confined to western, eastern, southern and south-eastern direction of the city guided by topographical constraints. Dominant transition has been from agricultural cropland and vacant land to low dense built up area corroborated by the striking decline of $18.71 \mathrm{sq}$. km. (4.04 percent) in the extent of agricultural cropland. Built up area has also taken a toll on sparse vegetation which has registered a significant decline of approximately $17 \mathrm{sq}$. km. (3.71 percent). Dense vegetation has also reduced in area by nearly $10 \mathrm{sq}$. $\mathrm{km}$. as a result of indiscriminate mining and deforestation activities. In central, northern and southern fringe area conversion of low dense built up to high dense built up is more evident.

\subsection{Spatial Patterns of LST}

Figure 5 (a) and (b) show the spatial distribution of day time summer LST in the study area in year 2000 and 2011 respectively.

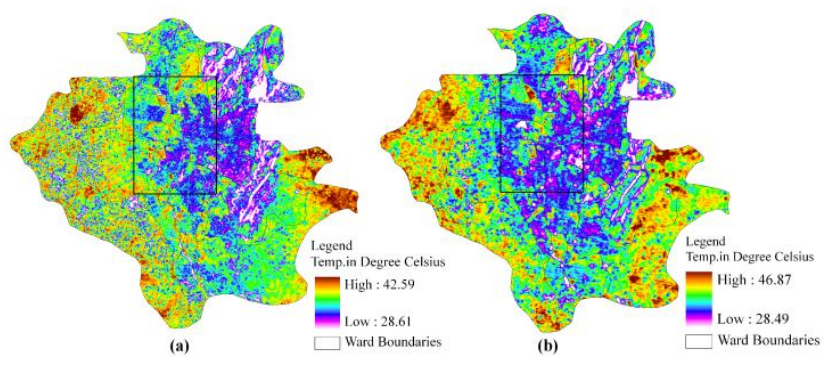

Figure 5. Land surface temperature map (a) 2000 (b) 2011

Pixel level LST ranged from $28.61{ }^{\circ} \mathrm{C}$ to $42.59{ }^{\circ} \mathrm{C}$ across the city in year 2000. Mean LST in the region was $38.46^{\circ} \mathrm{C}$ with a standard deviation of $1.57{ }^{\circ} \mathrm{C}$. Northern, north-eastern and central pat of the city recorded low to moderate $\left(34-39{ }^{\circ} \mathrm{C}\right.$ ) temperatures except for a few scattered pockets of high temperatures. Highest temperatures were observed in east, south-west and north-west parts of the city.

Mean LST in the region recorded a significant increase of approximately $4{ }^{\circ} \mathrm{C}$ in 2011 . It ranged from $28.49{ }^{\circ} \mathrm{C}$ to 46.87 ${ }^{\circ} \mathrm{C}$ across the city. Mean LST in the region in 2011 increased to $41.29^{\circ} \mathrm{C}$ with a standard deviation of $1.69{ }^{\circ} \mathrm{C}$. New pockets of high temperature emerged in the south eastern part of the city. Already existing high temperature areas have intensified. On the contrary, the eastern part of the city has observed a significant decline in LST from high to moderate temperatures.

Figure 6 illustrates zonal LST change in context of associated direction and magnitude of change in built up area and vegetation. Zonal level mean LST has recorded an increase of more than $2^{\circ} \mathrm{C}$ in all the zones. The city is clearly divided into two parts - the eastern part where highest changes of the order of 2.5 to $4^{\circ} \mathrm{C}$ have occurred, and the western part where change is less than $2.5^{\circ} \mathrm{C}$. 


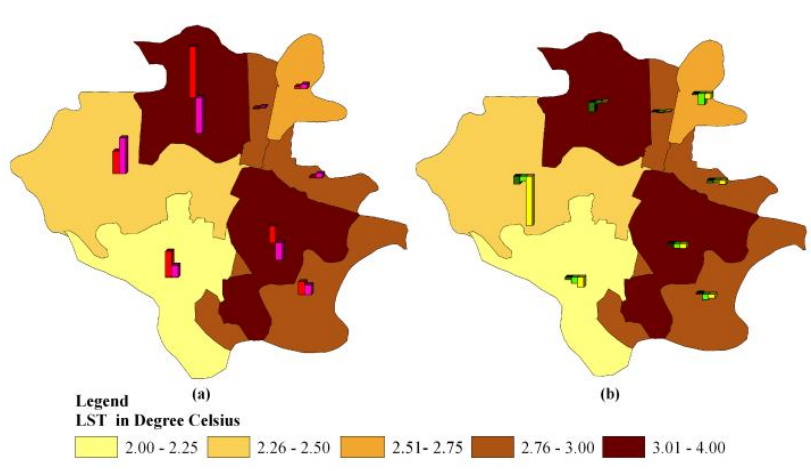

Figure 6. (a) Zonal change in LST and extent of high/low dense built up area (b) Zonal change in LST and extent of vegetation classes (colour of the bars correspond to the legend of Figure 3)

\subsection{Relationship between LST and Land Use/Land Cover}

Results reveal that highest LST corresponds to bare soil areas, built up areas and agricultural fallow land. Water bodies record lowest LST values followed by vegetation classes. Correlation between LST and NDVI images is -0.562 in 2000 (significant at 0.5 percent level if significance) and -0.522 in 2011 (significant at 0.5 percent level of significance). The statistics underlines significant negative relationship between LST and abundance of vegetation cover. Highest increase in temperature is primarily associated with newly built up areas where built up and bare soil occur in mixed form as in western, southern, south eastern and eastern part of the city. Positive changes have also occurred in areas where marked densification of built up area has taken place as in northern part of the city. These areas also house the major industrial areas of the city.

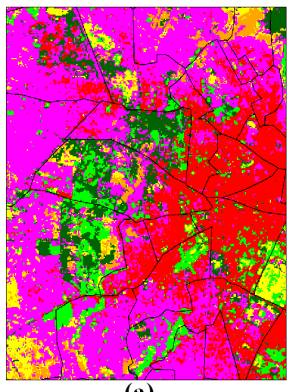

(a)

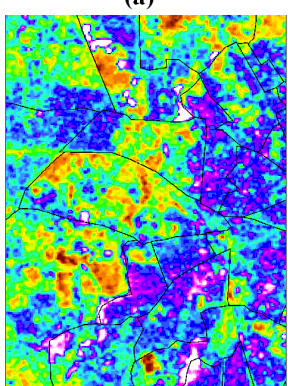

(c)

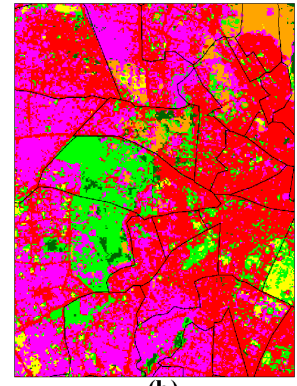

(b)

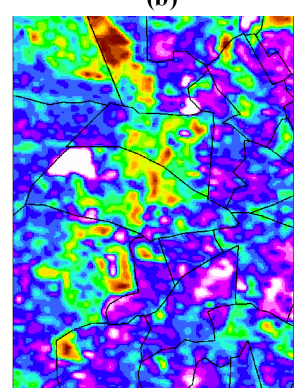

(d)
Figure 7. Subset representing major trends of LULC and associated LST changes (a) LULC map of 2000 (b) LULC map of 2011 (c) LST map of 2000 (d) LST map of 2011.

Figure 7 presents a zoomed view of the central part of the city wherein major types of transitions of land use land cover categories can be seen (Figure 7a \& b) and associated changes in temperature can be observed (Figure 7 c \& d). Northern part of the region has observed conversion of densely vegetated and vacant land to built up as well as considerable densification of built up area. The regions also records substantial rise in LST. Central part of the region shows drastic decline in dense vegetation. The area also records some pockets of intense heating. Extreme north east part shows change of densely vegetated area into vacant land which also corresponds to transition of area from lower to higher LST category.

The findings are corroborated by trends at zonal level. As evident from Figure 6, zones which have recorded highest positive change in mean LST have undergone substantial conversion of low dense to high dense built up area and reduction in vegetation as well as agricultural land. All zones have invariably witnessed a decline in vegetation cover and agricultural land. On the other hand increase in built up area, whether in the form of new areas as a part of urban expansion or densification of already existing ones, is also a common feature of all zones. This explains the overall trend of temperature rise of more than $2^{\circ} \mathrm{C}$ across the city.

\section{CONCLUSION}

Jaipur city is undergoing urbanization at a fast pace and need to accommodate ever increasing population has accelerated indiscriminate destruction of urban greenery and agricultural land during the past decade. Rapid spatial expansion and densification of built up area coupled with destruction of vegetation cover has resulted into a significant average rise of $2.99{ }^{\circ} \mathrm{C}$ temperature across the city which can potentially pose a serious threat to the urban micro-climate. Urban Heat Island effect has not only intensified but has also spread to newer areas.

There is a dire need for continuous monitoring of city's land use land cover dynamics and to devise rational, scientific and sustainable urban land use zonation plans. The study also shows the potential utility of remote sensing and GIS technology for effective and timely monitoring of spatial patterns and trends of physical growth of the city, to understand the associated changes in urban environment, to identify problem areas and to devise sustainable urban land use plans and policies so as to check the phenomenon of intensification of UHI.

\section{REFERENCES}

Buyantuyev A. and $\mathrm{Wu}, \mathrm{J} ., 2010$. Urban heat islands and landscape heterogeneity: linking spatiotemporal variations in surface temperatures to land-cover and socioeconomic patterns. Landscape Ecology, 25, pp. 17-33.

Chen, X. L., Wang, Q., Zheng, J. and Xiaobin, L., 2002. A study on urban thermal field in summer based on satellite remote sensing. Remote Sensing for Land and Resources, 4, pp. 55-59.

Chen, X.L., Zhao, H.M., Li, P.X. and Yin, Z. Y., 2006. Remote sensing image-based analysis of the relation between urban heat island and land use /land cover changes. Remote Sensing of Environment, 104, pp. 133-146.

Dai, X., Zhongyang, G., Zhang, L. and Li, D., 2010. Spatiotemporal exploratory analysis of urban surface temperature field 
in Shanghai, China. Stochastic Environmental Research \& Risk Assessment, 24, pp. 247-257.

Deosthali, V., 2000. Impact of rapid urban growth on heat and moisture islands in Pune City, India. Atmospheric Environment, 34, pp. 2745-2754.

Dousset, B. and Gourmelon, F., 2003. Satellite multi-sensor data analysis of urban surface temperatures and land cover. ISPRS Journal of Photogrammetry \& Remote Sensing, 58, pp. 43-54.

Gallo, K.P., Tarpley, J.D. and McNab, A.L., 1995. Assessment of urban heat island: a satellite perspective. Atmospheric Research, 37, pp. 37-43.

Giridharan, R., Ganesan, S. and Lau, S. S. Y., 2004. Daytime urban heat island effect in high-rise and high-density residential developments in Hong Kong. Energy and Buildings, 36(6), pp. 525-534.

Janssen, M., 1998. Modeling Global Change- The Art of Integrated Assessment Modeling. Elgar, Edward

Keller, C.F., 2008. Global warming: a review of mostly settled issue. Stochastic Environmental Research \& Risk Assessment, doi: 10.1007/s00477-008-0253-3.

Kim, Y. H. and Baik, J. J., 2002. Maximum Urban Heat Island Intensity in Seoul. Journal of Applied Meteorology, 41, pp. 651653.

Li, L., Tan, Y., Ying, S., Yu, Z., Li, Z. and Lan, H., 2014. Impact of land cover and population density on land surface temperature: case study in Wuhan, China. Journal of Applied Remote Sensing, 8, doi: 1117/1.JRS.8.084993.

Nieuwolt, S., 1966. The urban microclimate of Singapore. The Journal of Tropical Geography, 22, pp. 30-37.

Oke, T. R., 1987. Boundary Layer Climates (2nd edition). Methuen, London, pp. 435.

Owen, T.W., Carlson, T.N. and Gillies, R.R.,1998. An assessment of satellite remotely-sensed land cover parameters in quantitatively describing the climate effect of urbanization. International Journal of Remote Sensing, 19, pp. 1663-1681.

Schott, J. R. and Volchok, W. J., 1985. Thematic Dapper thermal infrared calibration. Photogrammetric Engineering and Remote Sensing, 51(9), pp. 1351-1357.

Streutker, D. R., 2003. Satellite-measured growth of the urban heat island of Houston, Texas. Remote Sensing of Environment, 85, pp. 282-289.

Tamerius, J.D., Wise E.K., Uejio, C.K., McCoy, A.L. and Comrie A.C., 2007. Climate and human health: synthesizing environmental complexity and uncertainty. Stochastic Environmental Research \& Risk Assessment, 21, pp. 601-613.

Tian, Q. and Xiangjun, M., 1998. Advances in study on vegetation indices. Advance in Earth Sciences, 13(4), pp. 327333.

Wan, Z. and Dozier, J.A., 1996. Generalized split-window algorithm for retrieving land-surface temperature from space. IEEE Trans Geosci Remote Sens, 34, pp. 892-905.
Weng, Q., 2009. Thermal infrared remote sensing for urban climate and environmental studies: methods, application and trends. ISPRS Journal of Photogrammetry and Remote Sensing, 64, pp. 335-344.

Weng, Q., Liu, H. and Lu, D., 2007. Assessing the effects of land use and land cover patterns on thermal conditions using landscape metrics in city of Indianapolis, United States. Urban Ecosystems, 10, pp. 203-219.

Xiao, R., Weng, Q., Ouyang, Z., Li, W., Schienke, E.W. and Zhang, W., 2008. Land surface temperature variation and major factors in Beijing, China. Photogrammetric Engineering \& Remote Sensing, 74 (4), pp. 451-461.

Yuan, F. and Bauer M.E., 2007. Comparison of impervious surface area and normalized difference vegetation index as indicators of surface heat island effects in Landsat imagery. Remote Sensing of Environment, 106, pp. 375-386.

Census of India, 2001a. District census handbook, Town directory of Jaipur, Directorate of Census Operations, Rajasthan, India.

Census of India, 2011b. District census handbook, Town directory of Jaipur, Directorate of Census Operations, Rajasthan, India.

JDA, 2011. Master Plan handbook. Jaipur Development Authority, Jaipur, Rajasthan, India

http://atmcorr.gsfc.nasa.gov 